\title{
Colloidal Bismuth Nanocrystals as a Model Anode Material for Rechargeable Mg-Ion Batteries: Atomistic and Mesoscale Insights
}

Kostiantyn V. Kravchyk, ${ }^{\dagger, \ddagger}$ Laura Piveteau, ${ }^{\dagger, \ddagger}$ Riccarda Caputo, ${ }^{\dagger, \perp}$ Meng He, ${ }^{\dagger, \ddagger}$ Nicholas P. Stadie, ${ }^{\dagger, \dagger, \# \odot ~}$ Maryna I. Bodnarchuk, Rainer T. Lechner, ${ }^{\S}$ and Maksym V. Kovalenko* ${ }^{\dagger},+\neq$

${ }^{\dagger}$ Department of Chemistry and Applied Biosciences, ETH Zürich, Vladimir-Prelog-Weg 1, Zurich, CH-8093 Switzerland

${ }^{\ddagger}$ Empa-Swiss Federal Laboratories for Materials Science and Technology, Überlandstrasse 129, Dübendorf, CH-8600 Switzerland

${ }^{\S}$ Institute of Physics, Montanuniversitaet Leoben, Franz-Josef-Strasse 18, A-8700 Leoben, Austria

Supporting Information

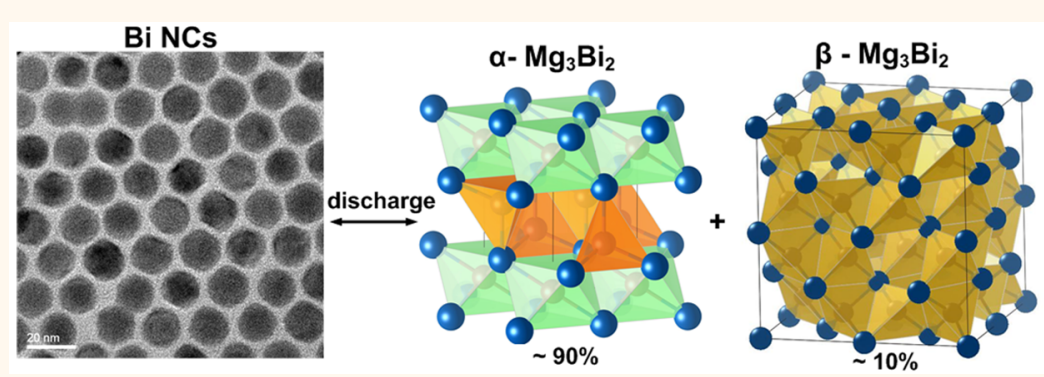

ABSTRACT: At present, the technical progress of secondary batteries employing metallic magnesium as the anode material has been severely hindered due to the low oxidation stability of state-of-the-art $\mathrm{Mg}$ electrolytes, which cannot be used to explore high-voltage ( $>3 \mathrm{~V}$ versus $\mathrm{Mg}^{2+} / \mathrm{Mg}$ ) cathode materials. All known electrolytes based on oxidatively stable solvents and salts, such as $\mathrm{Mg}\left(\mathrm{ClO}_{4}\right)_{2}$ and $\mathrm{Mg}$ bis(trifluoromethanesulfonimide), react with the metallic magnesium anode, forming a passivating layer at its surface and preventing the reversible plating and stripping of $\mathrm{Mg}$. Therefore, in a near-term effort to extend the upper voltage limit in the exploration of future candidate Mg-ion battery cathode materials, bismuth anodes have attracted considerable attention due to their efficient magnesiation and demagnesiation alloying reaction in such electrolytes. In this context, we present colloidal Bi nanocrystals (NCs) as a model anode material for the exploration of cathode materials for rechargeable $\mathrm{Mg}$-ion batteries. Bi NCs demonstrate a stable capacity of $325 \mathrm{mAh} \mathrm{g}^{-1}$ over at least 150 cycles at a current density of $770 \mathrm{~mA} \mathrm{~g}{ }^{-1}$, which is among the most-stable performance of $\mathrm{Mg}$-ion battery anode materials. First-principles crystal structure prediction methodologies and ex situ X-ray diffraction measurements reveal that the magnesiation of $\mathrm{Bi}$ NCs leads to the simultaneous formation of the low-temperature trigonal structure, $\alpha$ $\mathrm{Mg}_{3} \mathrm{Bi}_{2}$, and the high-temperature cubic structure, $\beta-\mathrm{Mg}_{3} \mathrm{Bi}_{2}$, which sheds insight into the high stability of this reversible alloying reaction. Furthermore, small-angle $X$-ray scattering measurements indicate that although the monodispersed, crystalline nature of the Bi NCs is indeed disturbed during the first discharge step, no notable morphological or structural changes occur in the following electrochemical cycles. The cost-effective and facile synthesis of colloidal Bi NCs and their remarkably high electrochemical stability upon magnesiation make them an excellent model anode material with which to accelerate progress in the field of $\mathrm{Mg}$-ion secondary batteries.

KEYWORDS: Mg-ion battery, magnesium, energy storage, nanocrystal, synthesis

I $\mathrm{n}$ recent years, investigations of electrode materials for rechargeable metal-ion batteries (e.g., Li-ion and emerging Na-ion batteries) have increasingly involved nanomaterials. In particular, monodispersde inorganic nanocrystals (NCs) and nanoparticles (NPs) of electrode materials are increasingly employed as well-defined model systems for controlling and studying the effects of particle size, composition, and morphology on electrochemical characteristics during battery operation (e.g., rate capability, cycling performance, etc.). Such model systems are also of interest for the effective nanoscale intermixing of active electrode materials with other components, ${ }^{1-8}$ typically also benefiting from their convenient solution-based handling. Due to very short internal diffusion paths, nanoscale materials are far less limited by their ionic and

Received: May 12, 2018

Accepted: August 7, 2018

Published: August 7, 2018 
electronic conductivities than their bulk counterparts. ${ }^{9-17}$ Nanomaterials can also withstand much-greater mechanical deformation during charge-discharge cycling, a problem facing all anode materials that operate via alloying with either $\mathrm{Li}$ (such as $\mathrm{Si}, \mathrm{Sn}, \mathrm{Sb}$, and $\mathrm{Ge}$ ) or $\mathrm{Na}$ (such as $\mathrm{Sn}, \mathrm{Sb}$, and $\mathrm{P}$ ), which is accompanied by large volumetric expansion (e.g., $100-400 \%){ }^{3,18-37}$ Overall, these favorable attributes of nanomaterial-based electrodes have allowed the variety of inorganic compounds that can be explored as reversible $\mathrm{Li}$ - and Na-ion storage media to significantly widen, at least in a laboratory setting. Although the cost and complexity of the synthesis of such nanomaterials can be commercially prohibitive, the insights gained from investigating such precisely tunable model systems can guide the development of economic production routes or definitively determine whether certain materials should be pursued at all.

Herein, we apply the utility of monodisperse metallic NCs as model electrode materials to the investigation of Mg-ion batteries. Secondary batteries based on magnesium arise as a result of a fundamental shortcoming of $\mathrm{Li}^{-}$and $\mathrm{Na}$-ion batteries in that neither metallic lithium nor sodium (the densest and conceptually simplest sources of $\mathrm{Li}$ and $\mathrm{Na}$ ions) can safely be employed as the negative electrode material (anode) in their corresponding metal-ion batteries. ${ }^{38-41}$ The well-known reason for this is the formation of dendrites during cycling and the associated risks of electrical short-circuit and runaway exothermic reactions in addition to the highly pyrophoric nature of these metals. Graphite is the mostcommon anode in commercial Li-ion batteries, exhibiting a similar voltage profile to that of lithium metal but with a 10 fold lower charge-storage capacity. In conceptually analogous Mg-ion batteries (MIBs), however, metallic magnesium can in fact be employed as a safe and high capacity anode material, ${ }^{42-47}$ exhibiting both dendrite-free electroplating and lower pyrophoricity. Further, concerns regarding the future security of the supply of lithium and its geographically heterogeneous natural occurrence ${ }^{48}$ are not faced by magnesium, making MIBs an attractive alternative for largescale stationary energy storage applications; $\mathrm{Mg}$ is highly abundant in the Earth's crust $(2.3 \mathrm{wt} \%, \sim 1100$ times higher than $\mathrm{Li})^{49}$ and extremely inexpensive (3.1 USD kg-1 $\sim 20$ times lower than $\mathrm{Li}$ ). Importantly, as a pure elemental anode material, metallic magnesium exhibits volumetric and gravimetric capacities $\left(3833 \mathrm{mAh} \mathrm{cm}^{-3}\right.$ and $2205 \mathrm{mAh} \mathrm{g}^{-1}$, respectively) that are comparable with metallic lithium (2062 $\mathrm{mAh} \mathrm{cm}{ }^{-3}$ and $3861 \mathrm{mAh} \mathrm{g}^{-1}$, respectively) and sodium (1128 $\mathrm{mAh} \mathrm{cm}{ }^{-3}$ and $1166 \mathrm{mAh} \mathrm{g}^{-1}$, respectively) at a relatively low standard electrode potential $\left(0.69 \mathrm{~V}\right.$ versus $\mathrm{Li}^{+} / \mathrm{Li}$ or $0.35 \mathrm{~V}$ versus $\left.\mathrm{Na}^{+} / \mathrm{Na}\right){ }^{42,43,50,51}$ Lastly, the issue of irreversible capacity loss as a result of the formation of a solid-electrolyte interface (SEI, arising from the reduction of the electrolyte at low anodic potentials), which is a significant complexity facing a large number of Li-ion and Na-ion anode materials, is not an important issue for MIBs.

Secondary MIBs, nevertheless, face several obstacles to overcome before practical deployment will be possible, primarily with respect to significant electrochemical incompatibilities between the currently identified candidate anode, electrolyte, and cathode materials. While $\mathrm{Mg}^{2+}$ ions have a similar radius to $\mathrm{Li}^{+}$ions, their bivalent charge causes strong Coulomb interactions within typical polar solid-state conductors, leading to diffusivity that is orders of magnitude lower and issues with respect to the electrolyte chemistry. ${ }^{42,43,46,52-57}$
Electrolytes that are favored for their ability to reversibly strip and deposit $\mathrm{Mg}^{2+}$ ions on a metallic magnesium anode are typically highly reducing compounds themselves or contain such solvents, invariably causing undesirable oxidation at the cathode and therefore restricting practical operation to within 2-3.0 V versus $\mathrm{Mg}^{2+/} \mathrm{Mg}^{42,58-62}$ This obstacle is faced by all studies of cathode materials for MIBs, ${ }^{42-44,46,47,53,55-57,61-82}$ and, as a result, Chevrel-phase $\mathrm{Mo}_{6} \mathrm{~S}_{8}$ has remained the benchmark cathode material for MIBs despite its modest gravimetric capacity (typically measured to be $80-100 \mathrm{mAh}$ $\mathrm{g}^{-1}$, with a theoretical limit of $\left.128 \mathrm{mAh} \mathrm{g}^{-1}\right) .{ }^{45}$ At the same time, low-cost, conventional electrolytes based on oxidationstable salts [e.g., $\mathrm{Mg}\left(\mathrm{ClO}_{4}\right)_{2}, \mathrm{Mg}$ bis(trifluoromethanesulfonimide) $\left(\mathrm{Mg}(\mathrm{TFSI})_{2}\right)$, etc. $]$ in an appropriate solvent (e.g., acetonitrile or various ionic liquids) cannot be used together with a metallic magnesium anode due to the irreversible deposition and stripping of $\mathrm{Mg}^{2+}$ and the formation of an insulating passivation layer (in contrast to the formation of a conductive SEI in Li-ion batteries). ${ }^{46,54,75,83}$

While the very concept of the Mg-ion battery is founded on the eventual use of metallic magnesium as the anode material, it would be of great interest for basic research purposes to establish a model anode material that is stable at higher voltages and fast enough to enable a broader search for suitable electrolytes and cathode materials. Such a high-capacity model Mg-ion anode material could be chosen from several elements that readily alloy with $\mathrm{Mg}$ and their multinary compounds by electrochemical means at room temperature. Numerous recent studies have been devoted to $\mathrm{Bi}^{84-94} \mathrm{Sb}^{86} \mathrm{Sn},{ }^{17,95,96} \mathrm{~Pb},{ }^{97}$ In, ${ }^{98} \mathrm{Sb}_{1-x} \mathrm{Bi}_{x},{ }^{99} \mathrm{InBi}^{100}$ and $\beta$-SnSb, ${ }^{101,102}$ all seeking an understanding of the electrochemical behavior of these electrode materials, the atomistic details of ion insertion and deinsertion, and the mesoscale evolution of the electrode during cycling. Bismuth serves as an especially simple model material because it electrochemically alloys with $\mathrm{Mg}$ at room temperature, forming $\mathrm{Mg}_{3} \mathrm{Bi}_{2}$. While the gravimetric chargestorage capacity of $\mathrm{Bi}$ is an order of magnitude lower than that of metallic $\mathrm{Mg}$, the theoretical volumetric charge-storage capacity of $\mathrm{Bi}\left(3783 \mathrm{mAh} \mathrm{cm} \mathrm{cm}^{-3}\right)$ compares very favorably with that of metallic $\mathrm{Mg}\left(3833 \mathrm{mAh} \mathrm{cm}^{-3}\right)$ in addition to metallic $\mathrm{Li}\left(2062 \mathrm{mAh} \mathrm{cm}^{-3}\right)$ and $\mathrm{Na}\left(1128 \mathrm{mAh} \mathrm{cm}^{-3}\right)$. The gravimetric charge-storage capacity of $\mathrm{Bi}$ is, in any case, not a limiting factor in the overall energy storage capacity of full MIB cells at the present time due to the much-lower capacity of available cathode materials. Altogether, bismuth is, therefore, an optimal model anode for future research in the field of complete Mg-ion battery systems.

Herein, we report the synthesis and electrochemical characterization of monodispersed colloidal Bi NCs as an ideal model anode material for MIBs in the laboratory setting. We present atomistic and mesoscale studies of the magnesiation of bismuth by combining first-principles calculations and experimental studies of monodispersed colloidal Bi NCs. Density functional theory (DFT) methodologies were employed to predict the thermodynamically stable crystalline phases in the $\mathrm{Mg}-\mathrm{Bi}$ system. The simulated $\mathrm{X}$-ray powder diffraction (XRD) patterns of the relevant $\mathrm{Mg}_{x} \mathrm{Bi}$ phases were then compared with the measured diffraction patterns of ex situ measured samples of Bi NCs at various stages during electrochemical discharge-charge cycling, including samples collected after 100 cycles. The evolution of the mesoscale morphology of the as-prepared $\mathrm{Bi} \mathrm{NC}$ anodes during electrochemical cycling was then assessed via small- 


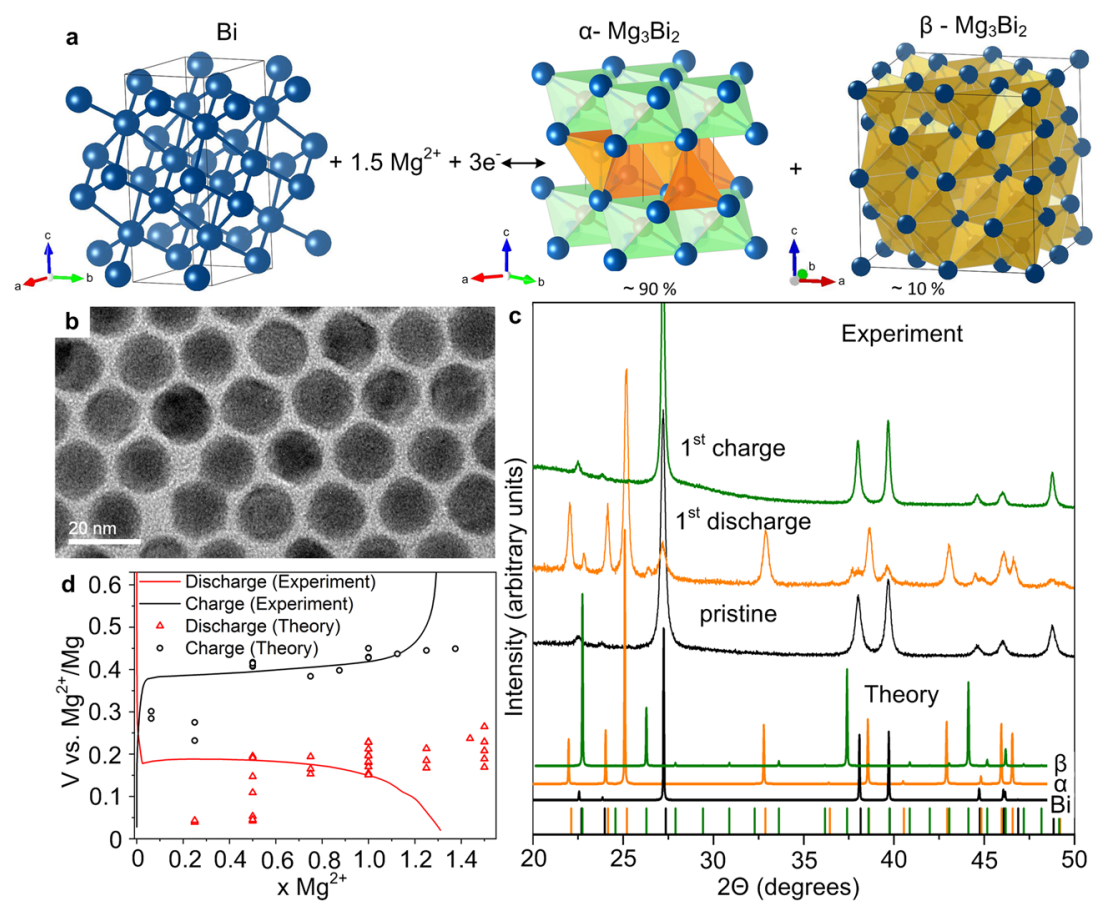

Figure 1. (a) Electrochemical magnesiation reaction of bismuth and the crystal structures of the relevant phases: elemental Bi (hexagonal), $\alpha-\mathrm{Mg}_{3} \mathrm{Bi}_{2}$ (trigonal), and $\beta-\mathrm{Mg}_{3} \mathrm{Bi}_{2}$ [cubic (simulated)]. The polyhedra show the tetrahedral (yellow) and octahedral (green) coordination environments of $\mathrm{Mg}$ by $\mathrm{Bi}$ atoms. (b) Transmission electron micrograph (TEM) of $18 \mathrm{~nm} \mathrm{Bi} \mathrm{NCs} \mathrm{prior} \mathrm{to} \mathrm{electrode} \mathrm{fabrication.} \mathrm{(c)}$ Experimental powder X-ray diffraction (XRD) patterns of pristine (as-prepared) and discharged and charged Bi NC electrodes and simulated patterns of the three relevant $\mathrm{Mg}_{x} \mathrm{Bi}$ phases identified in panel a. (d) Calculated and measured voltage profiles of the discharge and charge reactions for Bi $\mathrm{NCs}$, expressed in volts per mole of $\mathrm{Mg}$.

angle X-ray scattering (SAXS) techniques. Together, these results lead to a more-complete understanding of the electrochemical cycling behavior of Bi NC anodes, enabling future methodological studies of the integration of the anode, electrolyte, and cathode toward next-generation $\mathrm{Li}$ - and $\mathrm{Na}$ free battery concepts.

\section{RESULTS AND DISCUSSION}

Atomistic Insights into the Magnesiation of $\mathrm{Bi}$. By combining crystal-structure prediction methodologies and total-energy DFT calculations, as detailed in the Methods section, the insertion of $\mathrm{Mg}$ into elemental $\mathrm{Bi}$ was found to take place through an alloying mechanism, leading to the coformation of two stable phases (see Figures 1a, S1, and S2 and Table S1). These two phases comprise the commonly observed low-energy trigonal structure, $\alpha-\mathrm{Mg}_{3} \mathrm{Bi}_{2},{ }^{103}$ and the higher energy cubic structure, $\beta-\mathrm{Mg}_{3} \mathrm{Bi}$. Experimentally, the trigonal structure is typically observed at ambient temperature, and the cubic structure is stable above $976 \mathrm{~K}^{103}$ To the best of our knowledge, the crystal structure of $\beta-\mathrm{Mg}_{3} \mathrm{Bi}_{2}$ has not previously been characterized experimentally, although it has been suggested as having the $\mathrm{Mg}_{3} \mathrm{As}_{2}$ structure type. ${ }^{104}$

The enthalpies of formation of the $\alpha$ - and $\beta-\mathrm{Mg}_{3} \mathrm{Bi}_{2}$ phases are calculated to be -115.13 and $-99.33 \mathrm{~kJ} \mathrm{~mol}^{-1}$, respectively. The most-important structural difference between these two polymorphs of $\mathrm{Mg}_{3} \mathrm{Bi}_{2}$ is the coordination environment(s) of the $\mathrm{Mg}$ atoms. In the $\alpha$-phase trigonal structure, there are two non-equivalent $\mathrm{Mg}$ sites (Figure $\mathrm{S} 1$ ): one in the center of a perfect, edge-sharing $\mathrm{Bi}$ octahedron (octahedral $\mathrm{Mg}, 1 \mathrm{a}$ site) and one in the center of a distorted (distortion index: $0.013 \AA$ ), edge-sharing $\mathrm{Bi}$ tetrahedron (tetrahedral $\mathrm{Mg}, 2 d$ site). In the $\beta$-phase cubic structure, all of the $\mathrm{Mg}$ sites are symmetrically equivalent and occupy the centers of distorted, edge-sharing $\mathrm{Bi}$ tetrahedra, which have a low distortion index of $0.009 \AA$. Interestingly, the cubic $\beta$ $\mathrm{Mg}_{3} \mathrm{Bi}_{2}$ structure predicted herein differs from that reported by Barnes et al. ${ }^{104}$ Therein, only the neutron diffraction pattern lattice parameter was predicted, but the exact crystallographic space group was not found. It was hypothesized that $\beta-\mathrm{Mg}_{3} \mathrm{Bi}_{2}$ has the same space group as $\alpha$-AgI and $\alpha-\mathrm{Ag}_{2} \mathrm{Se}$ (that is, a body-centered cubic $\operatorname{Im} \overline{3} m$ structure, no. 229). ${ }^{104}$

Electrochemical MIB cells were subsequently prepared and analyzed at various stages during cycling to elucidate the magnesium insertion mechanism in Bi NCs. The magnesiation reaction of $\mathrm{Bi}$ NCs was carried out in a half-cell configuration using $\mathrm{Mg}$ foil as the counter and reference electrode and 0.2 $\mathrm{M} / 2 \mathrm{M} \mathrm{Mg}(\mathrm{BH} 4)_{2} / \mathrm{LiBH}_{4}$ in diglyme as the electrolyte. The Coulombic efficiency of $\mathrm{Mg}$ plaiting and stripping in $\mathrm{Mg}(\mathrm{BH} 4)_{2} / \mathrm{LiBH}_{4}$ was reported to be $100 \% .{ }^{53}$ The active anode material was composed of monodispersed $18 \mathrm{~nm} \mathrm{Bi}$ NCs (Figures $1 \mathrm{~b}$ and S3), synthesized using a surfactantassisted colloidal method as previously described. ${ }^{105}$ Room temperature powder XRD patterns of the Bi electrode were collected after electrochemical discharge ( $\mathrm{Mg}$ insertion), confirming the formation of two phases predicted in the simulations: the trigonal and cubic $\mathrm{Mg}_{3} \mathrm{Bi}_{2}$ phases. The hightemperature cubic phase, $\beta-\mathrm{Mg}_{3} \mathrm{Bi}_{2}$, was the minor component ( $\sim 10 \%$ within $24 \mathrm{~h}$ after magnesiation was started; Figure $1 \mathrm{c})$. The electrochemical potential during magnesiation (i.e., as a function of composition) calculated from the theoretical enthalpy of reaction (Figure S4) correlates well with the measured voltage profiles of electrodes prepared with $18 \mathrm{~nm} \mathrm{Bi}$ NCs (Figure 1d, galvanostatic cycling using magnesium borohydride as the electrolyte; see the Methods section for 
experimental details). Both galvanostatic discharge measurements and cyclic voltammetry (Figure S5) indicate that $\mathrm{Mg}$ ion insertion occurs at $0.2 \mathrm{~V}$ followed by removal at $0.4 \mathrm{~V}$. Flat magnesiation and demagnesiation plateau regions suggest the absence of any intermediate crystalline phases.

The magnesiation reaction,

$$
x \mathrm{Mg}+\mathrm{Bi} \rightarrow \mathrm{Mg}_{x} \mathrm{Bi}
$$

is calculated to be initially slightly endothermic until $x>0.5$, when the process becomes exothermic. Interestingly, between $0.5<x<1.25$, variable composition states were found, indicating the possibility of varying the $\mathrm{Mg}$ content in that range of composition by only small changes of energy. No other local minima are found in the composition range between $x=0$ and 1.5, in agreement with the experimental phase diagram. ${ }^{103}$ Volume changes during the magnesiation reaction were also calculated because the structural stability of an electrode material is directly related to the volume change upon the insertion and removal of ions. The insertion of $\mathrm{Mg}$ ions into $\mathrm{Bi}$ is predicted to induce only a slight volume increase between $0<x<0.25$; further insertion is accompanied by a linear dependence of the cell volume on the composition. When $x=1.5\left(\mathrm{Mg}_{3} \mathrm{Bi}_{2}\right)$ is reached, the cell volume has more than doubled compared to the demagnesiated state, enlarging from $30.98 \AA^{3}$ for elemental $\mathrm{Bi}$ to $138.13 \AA^{3}$ for $\alpha-\mathrm{Mg}_{3} \mathrm{Bi}_{2}$ (Figure S6).

First-principles structure prediction is particularly valuable as a tool to gain insight into the coordination environment of each atomic species and, hence, to determine the dominant factors (structural and energetic) that can impact the performance of a compound as an active electrode material. For example, vacancy formation energy and $\mathrm{Mg}$ atom conduction pathway isotropy and anisotropy are important properties to consider in the evaluation of electrode materials for MIBs. In this work, preliminary results indicate that at a low concentration of $\mathrm{Mg}$ vacancies, the enthalpies of vacancy formation in $\alpha-\mathrm{Mg}_{3} \mathrm{Bi}_{2}$ are comparable with octahedral and tetrahedral sites (e.g., +0.185 and $+0.173 \mathrm{eV}$, respectively, at $\left.\left[\mathrm{V}_{\mathrm{Mg}}\right]=0.125\right)$. At the same vacancy concentration, the enthalpy of Mg-vacancy formation in $\beta-\mathrm{Mg}_{3} \mathrm{Bi}_{2}$ is found to be significantly higher: $+0.408 \mathrm{eV}$. In addition, the migration of $\mathrm{Mg}$ atoms is very different between the two phases of $\mathrm{Mg}_{3} \mathrm{Bi}_{2}$. In trigonal $\alpha-\mathrm{Mg}_{3} \mathrm{Bi}_{2}, \mathrm{Mg}$-atom migration follows a tetrahedraloctahedral pathway according to molecular dynamics simulations at $300 \mathrm{~K}$. In the cubic $\beta-\mathrm{Mg}_{3} \mathrm{Bi}_{2}$, however, despite the fact that the $\mathrm{Mg}$ sites are all symmetrically equivalent, the wider distribution of $\mathrm{Mg}-\mathrm{Mg}$ distances causes the transport of $\mathrm{Mg}$ atoms to be anisotropic. The energetically favored route within $\beta-\mathrm{Mg}_{3} \mathrm{Bi}_{2}$ is the shortest $\mathrm{Mg}-\mathrm{Mg}$ pathway that is found to be along the crystallographic a-direction, as shown in Figure S2.

Mesoscale Insights into the Electrochemistry of Nanocrystalline Bi Anodes. In addition to the inherent phase transitions that occur during charge-discharge cycling, it is often the case that morphological changes play a significant role in electrochemical performance of nanoscale electrode materials, especially for materials that undergo large volumetric changes. We investigate these effects herein by starting with uniform, spherical, highly crystalline $18 \mathrm{~nm} \mathrm{Bi} \mathrm{NCs} \mathrm{and}$ monitor the changes (both to the individual NCs themselves and to the electrode as a whole) imparted as a result of electrode preparation and electrochemical cycling by perform- ing ex situ wide-angle XRD (Figure S7), TEM (Figure S8), and SAXS (Figure 2) measurements.

To prepare well-defined, model electrodes from uniform $\mathrm{Bi}$ NCs, several steps were undertaken prior to electrochemical cycling. First, the highly insulating capping ligands left over from the NC synthesis were removed via a soft treatment
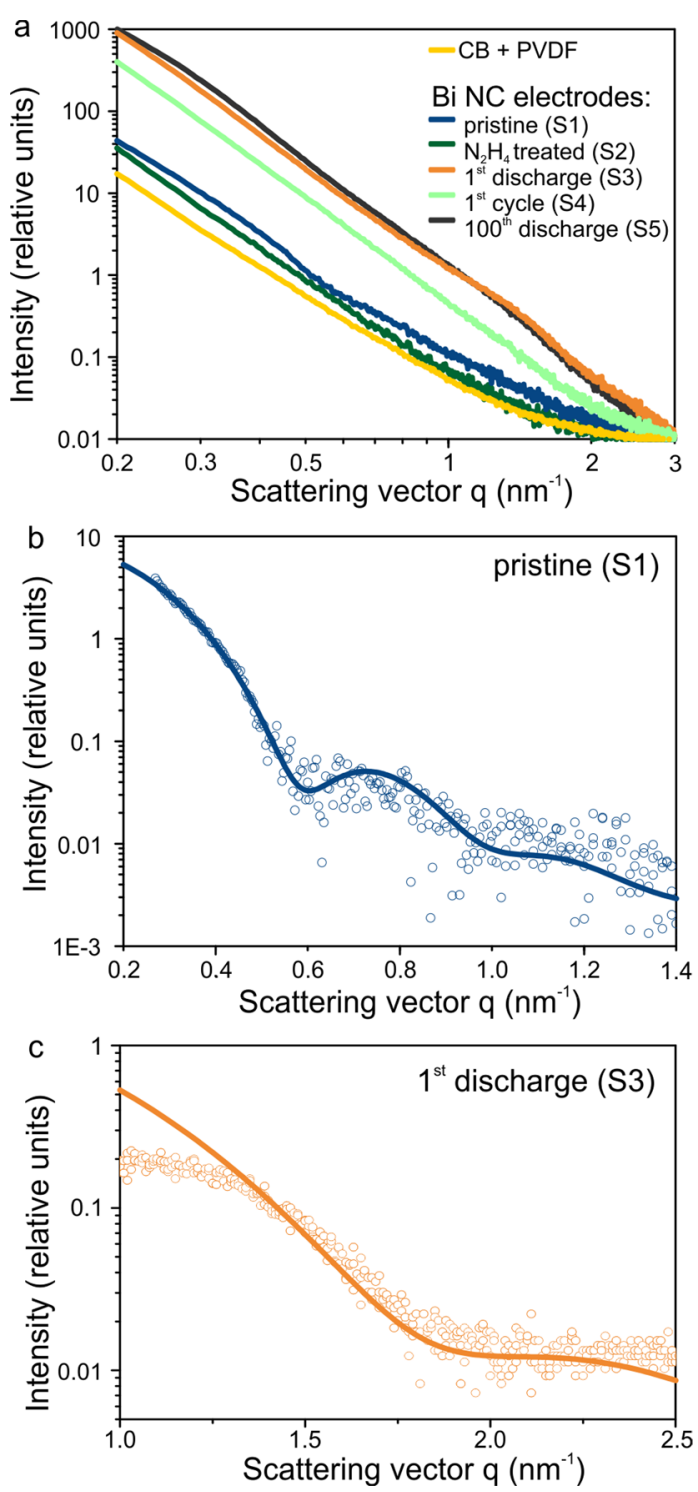

Figure 2. SAXS patterns of $18 \mathrm{~nm}$ Bi NC-based materials on $\mathrm{Cu}$ foil. The scattered intensity is plotted as a function of the reciprocal scattering vector, q. (a) $\log -\log$ plots of all SAXS patterns collected: carbon black with binder (CB plus PVDF, yellow) as a control and Bi NCs combined with CB and PVDF ("pristine electrode", blue), after hydrazine $\left(\mathrm{N}_{2} \mathrm{H}_{4}\right)$ treatment (green), after the 1st discharge (orange), after the 1st complete cycle (light green), and after the 100th discharge (gray). (b) Lognormal plot of the pristine Bi NC electrode SAXS pattern after subtracting the $\mathrm{CB}$ plus PVDF background. The measured data (circles) are fitted with a polydispersed sphere model (line) indicating an average diameter of $14.8 \pm 0.5 \mathrm{~nm}$. (c) Log-normal plot of the Bi NC electrode SAXS pattern after hydrazine treatment and the 1st discharge and after subtracting the $\mathrm{CB}$ plus PVDF background. The experimental data (circles) are fitted with a polydispersed sphere model (line), indicating an average particle size of $4.4 \pm 0.8 \mathrm{~nm}$. 
method using hydrazine in acetonitrile (ACN), a common ligand-stripping procedure. ${ }^{106-108}$ Subsequently, the bare Bi NCs were ball-mixed with polyvinylidene fluoride (PVDF) as a binding material and carbon black $(\mathrm{CB})$ as a conductive additive in $n$-methylpyrrolidone as a solvent, followed by casting and drying on copper foil as the current collector. The crystallite size of the monodisperse Bi NCs was found not to be affected by either the ligand removal procedure or the electrode fabrication, as determined by Scherrer analysis of the wide-angle XRD measurements (Figure S7; as-prepared electrodes are denoted as sample S1) and TEM studies (Figure S8). Just prior to assembling the electrochemical cells, the as-prepared $\mathrm{Bi} \mathrm{NC}$ electrodes were further treated with hydrazine to remove traces of surface oxides (denoted as sample S2), which were found to inhibit Mg-ion insertion (presumably by the formation of electronically and ionically insulating $\mathrm{MgO}$ ). This treatment was found to cause a doubling of the mean NC size (by XRD and TEM analysis), which may be attributed to the fusing of neighboring NCs once the surface oxides are removed. Subsequent electrochemical cycling (up to 100 cycles) did not cause a further increase in average NC size (Figures S7 and S8), suggesting that after the initial hydrazine-induced fusion, the larger NCs become sufficiently well-separated.

The mesoscale structure and morphology of complex materials can be sensitively probed using SAXS techniques, with applications ranging from the determination of the size and shape of crystalline and amorphous NPs to the symmetry and pore-to-pore spacing of ordered mesoporous materials or even to investigations of the structure of electrolyte ions in microporous electrodes. ${ }^{109}$ In this work, SAXS measurements of $18 \mathrm{~nm}$ Bi NC electrodes were performed at various stages of preparation and electrochemical cycling (Figure 2) to determine the average grain size and size distribution of the constituent particles within the overall electrode. The accessible length scale of these experiments was between 1 and $16 \mathrm{~nm}$, corresponding to scattering vectors, $q$, between 3.0 and $0.2 \mathrm{~nm}^{-1}$. A carbon-black anode combined with binder (CB plus PVDF, Figure 2a), investigated as a control sample, was found to exhibit the lowest integral scattering intensity, showing a linear dependence on $\mathrm{q}$ between 0.2 and $1 \mathrm{~nm}^{-1}$ with a Porod slope of -3.7 . This pattern is typical of mesostructured materials with fractal surfaces such as carbon black. ${ }^{110}$ Upon the fabrication of a pristine Bi NC electrode (sample S1), i.e., when Bi NCs are added to the CB plus PVDF mixture, the SAXS pattern exhibits the same background slope at 2.4 times higher integral scattering intensity. This higher intensity can be explained by the large scattering cross-section of Bi compared to carbon. The pristine sample also shows a local minimum at $0.6 \mathrm{~nm}^{-1}$ that can be caused by the scattering contribution of the shape function of the Bi NCs to the total scattering signal. After subtraction of the $\mathrm{CB}$ plus PVDF background (Figure 2b), the scattering profile for separated nanometer-sized particles is more apparent. A polydispersed sphere model can be used to fit the experimental SAXS data, indicating a mean particle diameter of $14.8 \pm 0.5$ $\mathrm{nm}$ with a size distribution of $14 \%$ (averaged 10 times), generally in good agreement with TEM images and wide-angle XRD patterns (Figures S3, S7, and S8). Moreover, the factor of 2.4 increase in integral scattering intensity due to the addition of $\mathrm{Bi}$ to the $\mathrm{CB}$ plus PVDF control electrode is consistent with calculations based on the comparison of a two-phase (carbon plus vacuum) and three-phase (carbon plus Bi plus vacuum) polydispersed sphere model using the known relative masses of $\mathrm{Bi}$ and carbon, the known electron densities of $\mathrm{Bi}$ and graphite, and a density of carbon black of $0.4 \mathrm{~g} \mathrm{~cm}^{-3}$. The subsequent treatment of the pristine electrode with hydrazine to remove trace oxides (sample S2) causes the minimum at $\sim 0.6 \mathrm{~nm}^{-1}$ to be less-pronounced, which is consistent with the NC size enlargement measured by wide-angle XRD.

After the first electrochemical discharge, i.e., magnesiation, of the hydrazine-treated electrode (sample S3), the SAXS intensity was found to be 16 times higher than that of the precycled, hydrazine-treated electrode (sample S2), and the SAXS pattern was found to exhibit a broad minimum at $\sim 1.9$ $\mathrm{nm}^{-1}$. Furthermore, upon the first charge, i.e., demagnesiation, of the discharged electrode (sample S4), the intensity was found to be reduced by a factor of 2, remaining 8 times higher than that of the pristine electrode (sample S1). The SAXS pattern of the same electrode after 100 discharges (sample S5) remains nearly identical to that of the sample after the first discharge, consistent with the high cycling stability of the electrodes as evidenced during electrochemical testing and discussed in the next section. The Porod slope of the SAXS pattern of the electrode after the first charge (sample S4) is -4.0, corresponding to a smoother surface of scattering particles. ${ }^{111}$ This reduction in the slope (from -3.7 for the electrode before cycling), and thus, smoothing of the $\mathrm{CB}$ surface can be explained by the filling of the mesopores (2-50 $\mathrm{nm}$ ) of the CB particles by electrolyte. In a simplified description, this mesopore filling corresponds to an increased volume of the $\mathrm{CB}$ particles and a slightly increased average electron density of the $\mathrm{CB}$ particles compared with particles without such incorporated ions. Both effects would also lead to an increased integral scattering intensity, as was observed. The higher intensity of the SAXS patterns of the discharged electrodes (samples S3 and S5) compared to that of the charged electrode (sample S4) indicates the successful incorporation of $\mathrm{Mg}$ ions into the Bi NCs. This increase is quantitatively validated by taking into account the volumetric expansion by a factor of 2 and decrease in electron density of $\mathrm{Mg}_{3} \mathrm{Bi}_{2}$ compared to $\mathrm{Bi}$.

The most-prominent feature of the SAXS pattern after the first discharge (and, likewise, for all subsequent post-discharge patterns) is the broad hump centered at $q=1.9 \mathrm{~nm}^{-1}$ (Figure $2 \mathrm{a}, \mathrm{c})$ corresponding to nanostructures with a length or regularity of $4.5 \mathrm{~nm}$ as fitted to a polydispersed sphere model (Figure 1c). The SAXS intensity below $1.4 \mathrm{~nm}^{-1}$ could not accurately be fitted by this method, which can be explained either by the agglomeration of $\sim 4.5 \mathrm{~nm}$ NPs, by the formation of $\sim 4.5 \mathrm{~nm}$ grains within larger $\mathrm{Mg}_{3} \mathrm{Bi}_{2}$ aggregates, or by a mixture of larger and smaller particles. The faint intensity modulation of the SAXS pattern of Bi NCs after 100 cycles (S5 in Figure 2a) indicates the existence of larger particles after cycling. The modulation between 0.2 and $0.7 \mathrm{~nm}^{-1}$ is attributed to structures in the size range between 20 to 40 $\mathrm{nm}$, which is consistent with the crystallite sizes derived from XRD analysis as shown in Figure S7. The wide-angle XRD peaks, however, do not show any pronounced broadening between the first charge and the 100th charge; instead, a moderate decrease in crystallite size from 35 to $25 \mathrm{~nm}$ is observed, accompanied by a pronounced decrease in peak intensity. This transition is reflected in the smooth and featureless SAXS pattern after the first discharge (S4 in Figure 2a) corresponding to scattering from large uniform particles compared to the more-modulated pattern after the 100th 
discharge (S5 in Figure 2a), comprising an additional hump at higher $q$ related to the formation of smaller particles. The lack of broadening in the wide-angle XRD peaks indicates that these newly formed, smaller particles are amorphous in nature, in accordance with the decrease in the Bragg peak intensities.

The results from this ex situ SAXS study of Bi NC anodes at various stages during electrode preparation and electrochemical cycling can be used to correlate structural changes in the electrode to the electrochemical behavior of the full-cell device. First, it is clear that the amorphization and reduction in size from 15 to $5 \mathrm{~nm}$ of a considerable fraction of the active $\mathrm{Bi}$ particles already occurs after the first discharge process and is therefore directly related to the incorporation of $\mathrm{Mg}$ into the NCs. In other words, this effect can be seen as a result of the formation of the $\alpha-\mathrm{Mg}_{3} \mathrm{Bi}_{2}$ and $\beta-\mathrm{Mg}_{3} \mathrm{Bi}_{2}$ phases. The corresponding peak in the SAXS pattern then remains constant over the next 100 charge-discharge cycles and shows only a slight shift to lower $q$ indicating a slight further increase in the active $\mathrm{Bi}$ particle diameter (S3 and S5 in Figure 2a). ${ }^{109} \mathrm{~A}$ schematic depiction of the size evolution of $18 \mathrm{~nm} \mathrm{Bi} \mathrm{NCs}$ upon electrode preparation, hydrazine treatment, and electrochemical cycling is given in Figure S9.

Half-Cell Electrochemical Performance: Capacity, Rate Capability, and Cyclability. The charge and discharge capacities of Bi NC electrodes (prepared with CB plus PVDF and treated with hydrazine to remove surface oxides) at a rate of $0.5 \mathrm{C}$ were found to be 331 and $335 \mathrm{mAh} \mathrm{g}^{-1}$ (corresponding to $x=1.3$ in Figure 1d), respectively, which corresponds to $\sim 90 \%$ of the theoretical capacity $(x=1.5)$. The effect of crystallite size on the rate performance of $\mathrm{Bi}$ anodes was investigated by preparing electrodes from spherical $\mathrm{Bi}$ NCs (both 10 and $18 \mathrm{~nm}$ ) and milled microcrystalline $\mathrm{Bi}(0.5-2$ $\mu \mathrm{m}$ crystallites, "bulk"), the details of which are shown in Figure S3. Surprisingly, relatively high capacities were measured for all cells even under discharge rates of up to 20 C (i.e., fully discharged in $3 \mathrm{~min}$ ) with a high Coulombic efficiency of $>98 \%$. The lowest capacities measured were for bulk $\mathrm{Bi}$ at high current rates (Figure 3a). No advantages were observed to be gained by reducing the size of Bi NCs from 18 to $10 \mathrm{~nm}$, with systematically poorer capacities measured at all rates. Cells incorporating $\mathrm{Bi} \mathrm{NCs}$ showed a high capacity retention of $93 \%$ after 150 cycles at a rate of $2 \mathrm{C}$ (for both 10 and $18 \mathrm{~nm} \mathrm{NCs).} \mathrm{Electrodes} \mathrm{containing} 18 \mathrm{~nm}$ Bi NCs also exhibited a noteworthy capacity retention of $54 \%$ after 4500 cycles at $20 \mathrm{C}$ (Figure S10). However, the capacity of electrodes prepared with bulk $\mathrm{Bi}$ were found to significantly decrease upon electrochemical cycling (Figure 3b).

Full-Cell Electrochemical Experiments Utilizing $\mathrm{Bi}$ Nanocrystal Anodes. The key potential benefit of Bi (and similar alloying materials) as a model anode for MIBs arises from its compatibility with more-desirable electrolytes within which metallic $\mathrm{Mg}$ does not reversibly electroplate. To demonstrate this utility, full-cell electrochemical experiments were conducted using $\mathrm{Mo}_{6} \mathrm{~S}_{8}$ (Chevrel phase) as a standard cathode. ${ }^{45}$ Anode-limited cells were assembled using anodes prepared from $18 \mathrm{~nm} \mathrm{Bi} \mathrm{NCs,} \mathrm{as} \mathrm{previously} \mathrm{described.} \mathrm{As} \mathrm{a}$ representative electrolyte (in which metallic $\mathrm{Mg}$ does not operate reversibly), a $1 \mathrm{M}$ solution of $\mathrm{Mg}(\mathrm{TFSI})_{2}$ in diglyme was used. Compared with borohydride-based electrolytes, $\mathrm{Mg}(\mathrm{TFSI})_{2}$ in diglyme is much safer and constitutes only earth-abundant elements and is therefore a desirable alternative. Hence, a more-common $\mathrm{Mg}\left(\mathrm{BH}_{4}\right)_{2} / \mathrm{LiBH}_{4}$ electrolyte was also tested for comparison. In both cases, $\mathrm{Mo}_{6} \mathrm{~S}_{8}$
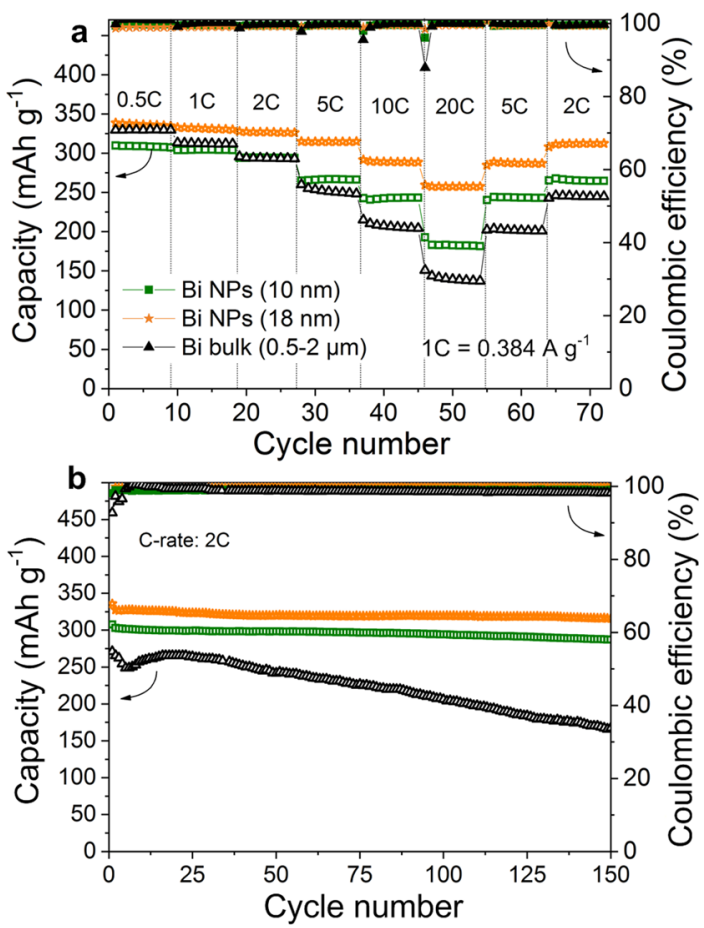

Figure 3. (a) Rate-capability measurements of Mg-ion half-cells incorporating $\mathrm{Bi}$ anodes derived from monodispersed Bi NCs (10 and $18 \mathrm{~nm})$ or microcrystalline $\mathrm{Bi}(0.5-2 \mu \mathrm{m}$, "bulk"). (b) Cycling stability of the same Bi anodes at a current density of $2 \mathrm{C}(0.77 \mathrm{~A}$ $\left.\mathrm{g}^{-1}\right)$. All electrodes were prepared with the same composition of $\mathrm{Bi}$ (64\%), CB (21\%), and PVDF (15\%) by weight, and a $0.2 \mathrm{M} / 2 \mathrm{M}$ solution of magnesium borohydride and lithium borohydride in diglyme was used as the electrolyte.

cathodes were first pre-charged (magnesiated) using half-cells with metallic $\mathrm{Mg}$ as the anode and $\mathrm{Mg}\left(\mathrm{BH}_{4}\right)_{2} / \mathrm{LiBH}_{4}$ as the electrolyte. With both $\mathrm{Mg}(\mathrm{TFSI})_{2}$ and borohydride electrolytes, $\mathrm{Bi} \mathrm{NC}$ anodes were found to exhibit similar capacities and fully reversible operation (Figures 4 and S11). Importantly, higher voltages (corresponding to higher energy-storage densities) and more-desirable voltage profiles were obtained with $\mathrm{Mg}(\mathrm{TFSI})_{2}$ as the electrolyte.

\section{CONCLUSIONS}

In this work, colloidal Bi NCs were demonstrated as a welldefined model system for understanding the effects of structural changes, crystallinity, and morphology on electrochemical properties of $\mathrm{Bi}$ anodes for $\mathrm{Mg}$-ion batteries upon discharge-charge (magnesiation-demagnesiation) cycling. Furthermore, $\mathrm{Bi}$ anodes can operate with a broader range of Mg-ion electrolytes, particularly with those made of oxidatively stable salts and solvents, offering important opportunities for the exploration of cathode materials operating above $3 \mathrm{~V}$ versus $\mathrm{Mg}^{2+} / \mathrm{Mg}$. While metallic $\mathrm{Mg}$ remains the eventual ideal anode material for MIBs, the short-term benefits of exploring a wide range of electrolyte and cathode combinations (together with $\mathrm{Bi}$ as the anode) could greatly accelerate research in the direction of high-energy-density, abundant element-based secondary batteries.

Specifically, it has been revealed that the intercalation of $\mathrm{Mg}$ within Bi NCs takes place through an alloying mechanism, leading to the simultaneous formation of $\alpha-\mathrm{Mg}_{3} \mathrm{Bi}_{2}$ and $\beta$ $\mathrm{Mg}_{3} \mathrm{Bi}_{2}$ as confirmed by XRD measurements. First-principles crystal-structure prediction methodologies enabled the identi- 

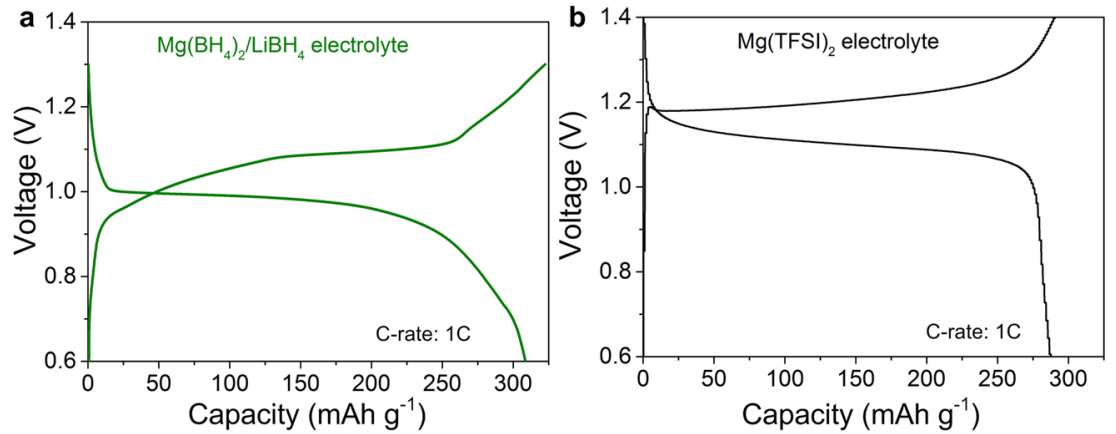

Figure 4. Typical discharge and charge voltage profiles of anode-limited full-cell $\mathrm{MIBs}\left(\mathrm{Bi}-\mathrm{Mo}_{6} \mathrm{~S}_{8}\right)$ at a rate of $1 \mathrm{C}(0.384 \mathrm{~A} \mathrm{~g}-1)$ with $(\mathrm{a})$ $\mathrm{Mg}\left(\mathrm{BH}_{4}\right)_{2}$ and $\mathrm{LiBH}_{4}$ and $(\mathrm{b}) \mathrm{Mg}(\mathrm{TFSI})_{2}$ as the electrolyte. The full-cell capacities are normalized to the mass of $\mathrm{Bi}$.

fication and characterization of the $\beta$ phase of $\mathrm{Mg}_{3} \mathrm{Bi}_{2}$ (cubic, $I \overline{3}$ space group). The first electrochemical discharge of the asprepared Bi NC electrode (after hydrazine treatment, which initially causes particle fusing) disturbs the monodispersed and crystalline nature of the active particles, leading to the formation of smaller nanostructures and amorphous particles. However, over the subsequent 100 discharge-charge cycles, the electrode structure and electrochemical performance remain nearly unchanged. Bi $\mathrm{NC}$ anodes were also found to exhibit a high retention of capacity upon extended cycling, losing only $7 \%$ of their initial capacity over 150 cycles at a rate of $2 \mathrm{C}\left(770 \mathrm{~mA} \mathrm{~g}^{-1}\right)$.

\section{METHODS}

Chemicals. Bismuth(III) chloride (99,999\%, Sigma-Aldrich), 2.7 $\mathrm{M} n$-butyllithium solution in heptane (Bu-Li, Aldrich), oleylamine (OLA, Acros), oleic acid (OA, 90\%, Aldrich), toluene (99.9\%, SigmaAldrich), ethanol (Fluka), hydrazine (Gerling Holz and Company), acetonitrile (ACN, max $0.005 \% \mathrm{H}_{2} \mathrm{O}$, Merck), potassium chloride (KCl, Fluka), molybdenum(IV) sulfide $\left(\mathrm{MoS}_{2}, 99 \%\right.$, Aldrich), copper sulfide (CuS, 99.5\%, STREM), and molybdenum (Mo, 99.7\%, Fluka).

Battery Components. Bismuth (325 mesh, 99.5\%, Alfa-Aesar), carbon black (CB, Super C65, provided by TIMCAL), Mg electrolyte [0.2 and $2 \mathrm{M}$ solution of magnesium borohydride $\left(\mathrm{Mg}\left(\mathrm{BH}_{4}\right)_{2}, 95 \%\right.$, Sigma-Aldrich] and lithium borohydride $\left(\mathrm{LiBH}_{4},>95 \%\right.$, SigmaAldrich) in diethylene glycol dimethyl ether (diglyme, anhydrous, 99.5\%, Sigma-Aldrich), conventional Mg electrolyte ( $0.25 \mathrm{M}$ solution of $\mathrm{Bis}$ (trifluoromethanesulfonyl)imide $\left(\mathrm{Mg}(\mathrm{TFSI})_{2}, 99.5 \%\right.$, in diglyme, Solvionic SA), glass-fiber separator (EUJ-grade, Hollingsworth and Vose Company Ltd.), PVDF (average MW $\approx 534 \mathrm{~g} \mathrm{~mol}^{-1}$, Sigma-Aldrich), and $\mathrm{N}$-methyl-2-pyrrolidone (NMP, 99\%, SigmaAldrich).

Synthesis of Bi NCs. In a typical synthesis of $\sim 18 \mathrm{~nm} \mathrm{Bi} \mathrm{NCs,}{ }^{105}$ $12 \mathrm{~mL}$ of dried OLA and $0.2 \mathrm{mmol}$ of $\mathrm{BiCl}_{3}(0.063 \mathrm{~g})$ were added into a $50 \mathrm{~mL}$ three-neck flask and dried under a vacuum for $20 \mathrm{~min}$ at $60{ }^{\circ} \mathrm{C}$ while stirring. In parallel, $3.6 \mathrm{mmol}$ of $\mathrm{Bu}-\mathrm{Li}(1.33 \mathrm{~mL})$ was prepared in an inert atmosphere glovebox. The temperature of the $\mathrm{OLA} / \mathrm{BiCl}_{3}$ solution was then increased to $130{ }^{\circ} \mathrm{C}$ under nitrogen, and the $\mathrm{Bu}-\mathrm{Li}$ solution was injected. The solution color turned dark brown immediately, indicating the formation of Bi NCs. After $300 \mathrm{~s}$, the reaction was quickly ended by the injecting $12 \mathrm{~mL}$ of anhydrous toluene and cooled to room temperature in an ice-water bath. Then, $0.2 \mathrm{~mL}$ of $\mathrm{OA}$ was added at $50{ }^{\circ} \mathrm{C}$. Bi NCs were precipitated by 25 $\mathrm{mL}$ of ethanol following centrifugation at $7000 \mathrm{rpm}$ for $4 \mathrm{~min}$. Then Bi NCs were redispersed in $5 \mathrm{~mL}$ of toluene containing $100 \mu \mathrm{L}$ of OA to replace the weakly bound OLA and then precipitated by $5 \mathrm{~mL}$ of ethanol followed by centrifugation at $7000 \mathrm{rpm}$ for $2 \mathrm{~min}$. Finally, the Bi NCs were re-dispersed in toluene. The synthesis of $10 \mathrm{~nm}$ Bi NCs has been conducted analogously to $18 \mathrm{~nm} \mathrm{Bi}$ NCs except for the $\mathrm{Bu}-$ $\mathrm{Li}$ injection temperature $\left(70{ }^{\circ} \mathrm{C}\right)$ and reaction time $(10 \mathrm{~s})$.

Ligand Removal of Bi NCs. To remove the organic capping ligands, NCs were precipitated with $\mathrm{EtOH}$, centrifuged and suspended in a solution of $0.8 \mathrm{~mL}$ of hydrazine in $25 \mathrm{~mL}$ of anhydrous acetonitrile. The suspension was stirred at room temperature for $2 \mathrm{~h}$. After centrifugation ( $8000 \mathrm{rpm}, 4 \mathrm{~min})$, the precipitate was washed three times with acetonitrile $(\sim 20 \mathrm{~mL})$ to remove residual hydrazine. Finally, NCs were separated from the solution by centrifugation ( $8000 \mathrm{rpm}, 4 \mathrm{~min})$ and dried for $12 \mathrm{~h}$ at room temperature under a vacuum.

Electrochemical Cell Preparation and Testing. Bi electrodes were prepared by the ball-milling of the respective Bi NCs after ligand removal or bulk Bi (64 wt \%) with carbon black (21 wt \%) and PVDF binder (15 wt \%) in NMP solvent for $1 \mathrm{~h}$ and casting the obtained slurry onto $\mathrm{Cu}$ foil. The onset of electrochemical oxidation for the $\mathrm{Cu}$ current collector occurs at $1.5 \mathrm{~V}$ versus $\mathrm{Mg}^{2+} / \mathrm{Mg}$ in $\mathrm{Mg}\left(\mathrm{BH}_{4}\right)_{2}$ / $\mathrm{LiBH}_{4}$ electrolyte (Figure S12). $\mathrm{Mo}_{6} \mathrm{~S}_{8}$ electrodes were prepared in the same way using $\mathrm{Mo}_{6} \mathrm{~S}_{8}$ powder $(80 \mathrm{wt} \%)$, carbon black (10 wt $\%)$, and PVDF binder (10 wt \%). $\mathrm{Mo}_{6} \mathrm{~S}_{8}$ was synthesized by the molten salt synthesis, as described elsewhere. ${ }^{112}$ The current collectors were then dried for $12 \mathrm{~h}$ at $80{ }^{\circ} \mathrm{C}$ in a vacuum oven. Additionally, shortly before assembling the batteries, the Bi electrodes were immersed in hydrazine solution in ACN (C = 25 vol \%) for $6 \mathrm{~h}$ following drying at $75{ }^{\circ} \mathrm{C}$ for $6 \mathrm{~h}$. In the case of bulk Bi electrodes, pure hydrazine was used instead of its solution. Caution: hydrazine is an extremely toxic and dangerously unstable liquid. Hydrazine treatment should be carried out only by appropriately trained personnel under air-free conditions (e.g., in a glovebox).

Coin-type cells were assembled in a glovebox using a one-layer glass fiber separator. Polished $\mathrm{Mg}$ metal served as both reference and counter electrode. The pair of electrolytes tested were 0.2 and $2 \mathrm{M}$ solutions of, respectively, magnesium borohydride and lithium borohydride, and diethylene glycol dimethyl ether and a $0.25 \mathrm{M}$ solution of $\mathrm{Mg}(\mathrm{TFSI})_{2}$ in diglyme were used. Half and full cells were cycled between $0.02-0.63 \mathrm{~V}$ and $0.220-1.35 \mathrm{~V}$, respectively, on an MPG2 multichannel workstation (Bio-Logic). The obtained capacities for half and full cells were normalized to the mass of Bi. Prior to electrochemical cycling, $\mathrm{Bi}$ electrodes were cycled for 10 cycles between $0.02-0.63 \mathrm{~V}$ using cyclic voltammetry at a scan rate of 0.1 $\mathrm{mV} \mathrm{s}^{-1}$. As is consistent with electrochemical impedance analysis (Figure S13), the impedance of the cell decreases considerably during the initial 10 cycles.

Material Characterization. TEM was performed using a Philips CM30 microscope operated at $300 \mathrm{kV}$. High-resolution TEM was performed using a JEOL 2200FS microscope at $200 \mathrm{kV}$. Samples were mounted on carbon-coated TEM grids (Ted-Pella). Wide-angle powder XRD measurements were performed using a STOE STADI P diffractometer. SAXS measurements were performed using a Bruker Nanostar on samples held under a vacuum.

DFT and Molecular Dynamics Simulations. The starting host lattice for the $\mathrm{Mg}-\mathrm{Bi}$ system was the rhombohedral structure of elemental bismuth. By combining the cluster expansion approach, interfaced with Quantum ESPRESSO DFT-based total energy calculations, and $A b$ Initio Random Structure Searching (AIRSS) coupled with CASTEP calculations, we mapped the potential energy surface (PES) in the full composition range of the $\mathrm{Mg}-\mathrm{Bi}$ system. 
The geometry optimizations of the final stable structures reported in the present work were obtained by using CASTEP calculations. We used norm-conserving pseudopotentials and reciprocal space representation of $\mathrm{Mg}$ and $\mathrm{Bi}$ atoms, whose valence shells contain, respectively, 10 electrons, $2 s^{2} 2 p^{6} 3 s^{2}$ states, and 15 electrons, $5 \mathrm{~d}^{10} 6 \mathrm{~s}^{2} 6 \mathrm{p}^{3}$ states. The different exchange-correlation functionals were checked in the lattice optimization to reproduce the lattice parameters as close as possible to the reported ones for the elemental phases, $\mathrm{Mg}$ and $\mathrm{Bi}$, and the binary phase, $\mathrm{Mg}_{3} \mathrm{Bi}_{2}$, which represent the initial state and the final state of the $\mathrm{Mg}-\mathrm{Bi}$-phase space considered in the present work. While the geometry optimization of the elemental phases, $\mathrm{Mg}$ and $\mathrm{Bi}$, better reproduced the respective lattice parameters by using the non-local potential CGA-PBE (Generalized Gradient Approximation with the functional PBE, after Perdew, Burke, and Ernzerhof ${ }^{13}$ ), the local potential LDA-CA-PZ (Local Density Approximation with the local functional of Ceperley and Alder, ${ }^{114}$ as parametrized by Perdew and Zunger ${ }^{115}$ ) reproduced lattice parameters of $\mathrm{Mg}_{3} \mathrm{Bi}_{2}$ closer to the experimentally reported ones. Based on that, in the final step of structure optimization of the binary phases, we used LDA potential with a cutoff energy of $720 \mathrm{eV}$ and a $k$ point mesh density of at least $0.02 \AA^{-1}$. To investigate the motion of $\mathrm{Mg}$ atoms in the charge reaction, we performed preliminary molecular dynamics calculations with NVT ensemble and by using a supercell composed of $2 \times 2 \times 2$ unit cells and $k$-point sampling at the $\gamma$ point. The temperature was set to $27{ }^{\circ} \mathrm{C}$ using a Hoover-Langevin thermostat and $1 \mathrm{fs}$ for the time step. The total simulation time was $10 \mathrm{ps}$.

\section{ASSOCIATED CONTENT}

\section{(5) Supporting Information}

The Supporting Information is available free of charge on the ACS Publications website at DOI: 10.1021/acsnano.8b03572.

A table showing lattice parameters. Figures showing $\alpha$ $\mathrm{Mg}_{3} \mathrm{Bi}_{2}$ structures, TEM analysis, calculated enthalpy, cyclic voltammograms, cell volume as a function of magnesium insertion, powder XRD patterns, a sizeevolution schematic, cycling stability, galvanostatic voltage profiles, and electrochemical impedance analysis. (PDF)

\section{AUTHOR INFORMATION}

\section{Corresponding Author}

*E-mail: mvkovalenko@ethz.ch.

ORCID $\odot$

Nicholas P. Stadie: 0000-0002-1139-7846

Maksym V. Kovalenko: 0000-0002-6396-8938

\section{Present Addresses}

${ }^{\perp}$ ICQMS, International Centre for Quantum and Molecular Structures, Department of Physics, Shanghai University, China "Department of Chemistry and Biochemistry, Montana State University, Bozeman, Montana 59717, United States

\section{Notes}

The authors declare no competing financial interest.

\section{ACKNOWLEDGMENTS}

This research is part of the activities of SCCER HeE, which is financially supported by Innosuisse, Swiss Innovation Agency. This work was also financially supported by ETH Zürich (grant no. ETH-56 12-2), the Swiss Federal Commission for Technology and Innovation (presently Innosuise, Swiss Innnovation Agency, CTI project no. 14698.2 PFIW-IW), and the Swiss National Science Foundation (SNF Ambizione Energy, grant no. PZENP2_154287). L.P. acknowledges financial support from Scholarship Fund of the Swiss Chemical
Industry (SSCI Award 2015). We thank Dr. Frank Krumeich for TEM measurements. The authors are grateful to the computational resources and research facilities of ETH Zurich (ETH Electron Microscopy Center, Department of Chemistry and Applied Biosciences) and Empa (Empa Electron Microscopy Center) for access to the instruments and for technical assistance.

\section{REFERENCES}

(1) Ulvestad, A.; Singer, A.; Clark, J. N.; Cho, H. M.; Kim, J. W.; Harder, R.; Maser, J.; Meng, Y. S.; Shpyrko, O. G. Topological Defect Dynamics in Operando Battery Nanoparticles. Science 2015, 348, 1344-1347.

(2) Xu, L.; Kim, C.; Shukla, A. K.; Dong, A.; Mattox, T. M.; Milliron, D. J.; Cabana, J. Monodisperse Sn Nanocrystals as a Platform for the Study of Mechanical Damage during Electrochemical Reactions with Li. Nano Lett. 2013, 13, 1800-1805.

(3) Oszajca, M. F.; Bodnarchuk, M. I.; Kovalenko, M. V. Precisely Engineered Colloidal Nanoparticles and Nanocrystals for Li-Ion and Na-Ion Batteries: Model Systems or Practical Solutions? Chem. Mater. 2014, 26, 5422-5432.

(4) Oh, M. H.; Yu, T.; Yu, S.-H.; Lim, B.; Ko, K.-T.; Willinger, M.G.; Seo, D.-H.; Kim, B. H.; Cho, M. G.; Park, J.-H.; Kang, K.; Sung, Y.-E.; Pinna, N.; Hyeon, T. Galvanic Replacement Reactions in Metal Oxide Nanocrystals. Science 2013, 340, 964-968.

(5) Liu, X. H.; Zhong, L.; Huang, S.; Mao, S. X.; Zhu, T.; Huang, J. Y. Size-Dependent Fracture of Silicon Nanoparticles During Lithiation. ACS Nano 2012, 6, 1522-1531.

(6) Aifantis, K. E.; Haycock, M.; Sanders, P.; Hackney, S. A. Fracture of Nanostructured Sn/C Anodes During Li-insertion. Mater. Sci. Eng., A 2011, 529, 55-61.

(7) Koo, B.; Xiong, H.; Slater, M. D.; Prakapenka, V. B.; Balasubramanian, M.; Podsiadlo, P.; Johnson, C. S.; Rajh, T.; Shevchenko, E. V. Hollow Iron Oxide Nanoparticles for Application in Lithium Ion Batteries. Nano Lett. 2012, 12, 2429-2435.

(8) Wang, S.; He, M.; Walter, M.; Krumeich, F.; Kravchyk, K. V.; Kovalenko, M. V. Monodisperse $\mathrm{CoSn}_{2}$ and $\mathrm{FeSn}_{2}$ Nanocrystals as High-Performance Anode Materials for Lithium-Ion Batteries. Nanoscale 2018, 10, 6827-6831.

(9) Chan, C. K.; Peng, H.; Liu, G.; McIlwrath, K.; Zhang, X. F.; Huggins, R. A.; Cui, Y. High-Performance Lithium Battery Anodes Using Silicon Nanowires. Nat. Nanotechnol. 2008, 3, 31-35.

(10) Magasinski, A.; Dixon, P.; Hertzberg, B.; Kvit, A.; Ayala, J.; Yushin, G. High-Performance Lithium-Ion Anodes Using a Hierarchical Bottom-Up Approach. Nat. Mater. 2010, 9, 353-358.

(11) Kovalenko, I.; Zdyrko, B.; Magasinski, A.; Hertzberg, B.; Milicev, Z.; Burtovyy, R.; Luzinov, I.; Yushin, G. A Major Constituent of Brown Algae for Use in High-Capacity Li-Ion Batteries. Science 2011, 334, 75-79.

(12) Chockla, A. M.; Klavetter, K. C.; Mullins, C. B.; Korgel, B. A Tin-Seeded Silicon Nanowires for High Capacity Li-Ion Batteries. Chem. Mater. 2012, 24, 3738-3745.

(13) Kravchyk, K. V.; Zünd, T.; Wörle, M.; Kovalenko, M. V.; Bodnarchuk, M. I. $\mathrm{NaFeF}_{3}$ Nanoplates as Low-Cost Sodium and Lithium Cathode Materials for Stationary Energy Storage. Chem. Mater. 2018, 30, 1825-1829.

(14) Guntlin, C. P.; Zund, T.; Kravchyk, K. V.; Worle, M.; Bodnarchuk, M. I.; Kovalenko, M. V. Nanocrystalline $\mathrm{FeF}_{3}$ and $\mathrm{MF}_{2}$ $(\mathrm{M}=\mathrm{Fe}, \mathrm{Co}$, and $\mathrm{Mn})$ from Metal Trifluoroacetates and Their Li(Na)-Ion Storage Properties. J. Mater. Chem. A 2017, 5, 73837393.

(15) Oszajca, M. F.; Kravchyk, K. V.; Walter, M.; Krieg, F.; Bodnarchuk, M. I.; Kovalenko, M. V. Colloidal $\mathrm{BiF}_{3}$ Nanocrystals: a Bottom-Up Approach to Conversion-Type Li-Ion Cathodes. Nanoscale 2015, 7, 16601-16605.

(16) Kim, C.; Adil, A. A.; Bayliss, R. D.; Kinnibrugh, T. L.; Lapidus, S. H.; Nolis, G. M.; Freeland, J. W.; Phillips, P. J.; Yi, T.; Yoo, H. D.; Kwon, B. J.; Yu, Y.-S.; Klie, R.; Chupas, P. J.; Chapman, K. W.; 
Cabana, J. Multivalent Electrochemistry of Spinel $\mathrm{Mg}_{\mathrm{x}} \mathrm{Mn}_{3-\mathrm{x}} \mathrm{O}_{4}$ Nanocrystals. Chem. Mater. 2018, 30, 1496-1504.

(17) Yaghoobnejad Asl, H.; Fu, J.; Kumar, H.; Welborn, S. S.; Shenoy, V. B.; Detsi, E. In Situ Dealloying of Bulk $\mathrm{Mg}_{2} \mathrm{Sn}$ in Mg-Ion Half Cell as an Effective Route to Nanostructured Sn for High Performance Mg-Ion Battery Anodes. Chem. Mater. 2018, 30, 18151824.

(18) Hayner, C. M.; Zhao, X.; Kung, H. H. Materials for Rechargeable Lithium-Ion Batteries. Annu. Rev. Chem. Biomol. Eng. 2012, 3, 445-471.

(19) Palomares, V.; Casas-Cabanas, M.; Castillo-Martínez, E.; Han, M. H.; Rojo, T. Update on Na-Based Battery Materials. A Growing Research Path. Energy Environ. Sci. 2013, 6, 2312-2337.

(20) Park, C.-M.; Kim, J.-H.; Kim, H.; Sohn, H.-J. Li-Alloy Based Anode Materials for Li Secondary Batteries. Chem. Soc. Rev. 2010, 39, $3115-3141$.

(21) Kim, Y.; Park, Y.; Choi, A.; Choi, N. S.; Kim, J.; Lee, J.; Ryu, J. H.; Oh, S. M.; Lee, K. T. An Amorphous Red Phosphorus/Carbon Composite as a Promising Anode Material for Sodium Ion Batteries. Adv. Mater. 2013, 25, 3045-3049.

(22) Goriparti, S.; Miele, E.; De Angelis, F.; Di Fabrizio, E.; Proietti Zaccaria, R.; Capiglia, C. Review on Recent Progress of Nanostructured Anode Materials for Li-Ion Batteries. J. Power Sources 2014, 257, 421-443.

(23) Nitta, N.; Wu, F.; Lee, J. T.; Yushin, G. Li-Ion Battery Materials: Present and Future. Mater. Today 2015, 18, 252-264.

(24) Dahbi, M.; Yabuuchi, N.; Kubota, K.; Tokiwa, K.; Komaba, S. Negative Electrodes for Na-Ion Batteries. Phys. Chem. Chem. Phys. 2014, 16, 15007-15028.

(25) Kim, S.-W.; Seo, D.-H.; Ma, X.; Ceder, G.; Kang, K. Electrode Materials for Rechargeable Sodium-Ion Batteries: Potential Alternatives to Current Lithium-Ion Batteries. Adv. Energy Mater. 2012, 2, $710-721$.

(26) Palomares, V.; Serras, P.; Villaluenga, I.; Hueso, K. B.; Carretero-Gonzalez, J.; Rojo, T. Na-Ion Batteries, Recent Advances and Present Challenges to Become Low Cost Energy Storage Systems. Energy Environ. Sci. 2012, 5, 5884-5901.

(27) Obrovac, M. N.; Chevrier, V. L. Alloy Negative Electrodes for Li-Ion Batteries. Chem. Rev. 2014, 114, 11444-11502.

(28) Kim, Y.; Ha, K.-H.; Oh, S. M.; Lee, K. T. High-Capacity Anode Materials for Sodium-Ion Batteries. Chem. - Eur. J. 2014, 20, 1198011992.

(29) Su, X.; Wu, Q.; Li, J.; Xiao, X.; Lott, A.; Lu, W.; Sheldon, B. W.; $\mathrm{Wu}, \mathrm{J}$. Silicon-Based Nanomaterials for Lithium-Ion Batteries: A Review. Adv. Energy Mater. 2014, 4, 1300882.

(30) Kundu, D.; Talaie, E.; Duffort, V.; Nazar, L. F. The Emerging Chemistry of Sodium Ion Batteries for Electrochemical Energy Storage. Angew. Chem., Int. Ed. 2015, 54, 3431-3448.

(31) Walter, M.; Erni, R.; Kovalenko, M. V. Inexpensive Antimony Nanocrystals and Their Composites with Red Phosphorus as HighPerformance Anode Materials for Na-Ion Batteries. Sci. Rep. 2015, 5, 08418 .

(32) Walter, M.; Bodnarchuk, M. I.; Kravchyk, K. V.; Kovalenko, M. V. Evaluation of Metal Phosphide Nanocrystals as Anode Materials for Na-Ion Batteries. Chimia 2015, 69, 724-728.

(33) Caputo, R. An Insight into Sodiation of Antimony from FirstPrinciples Crystal Structure Prediction. J. Electron. Mater. 2016, 45, 999-1010.

(34) Liu, J.; Wang, S.; Kravchyk, K.; Ibáñez, M.; Krumeich, F.; Widmer, R.; Nasiou, D.; Meyns, M.; Llorca, J.; Arbiol, J.; Kovalenko, M. V.; Cabot, A. SnP Nanocrystals as Anode Materials for Na-Ion Batteries. J. Mater. Chem. A 2018, 6, 10958-10966.

(35) He, M.; Kravchyk, K.; Walter, M.; Kovalenko, M. V. Monodisperse Antimony Nanocrystals for High-Rate Li-Ion and Na-Ion Battery Anodes: Nano versus Bulk. Nano Lett. 2014, 14, $1255-1262$.

(36) Kravchyk, K.; Protesescu, L.; Bodnarchuk, M. I.; Krumeich, F.; Yarema, M.; Walter, M.; Guntlin, C.; Kovalenko, M. V. Monodisperse and Inorganically Capped $\mathrm{Sn}$ and $\mathrm{Sn} / \mathrm{SnO}_{2}$ Nanocrystals for High-
Performance Li-Ion Battery Anodes. J. Am. Chem. Soc. 2013, 135, 4199-4202.

(37) He, M.; Walter, M.; Kravchyk, K. V.; Erni, R.; Widmer, R.; Kovalenko, M. V. Monodisperse SnSb Nanocrystals for Li-Ion and Na-Ion Battery Anodes: Synergy and Dissonance Between Sn and Sb. Nanoscale 2015, 7, 455-459.

(38) Tarascon, J. M.; Armand, M. Issues and Challenges Facing Rechargeable Lithium Batteries. Nature 2001, 414, 359-367.

(39) Li, Z.; Huang, J.; Yann Liaw, B.; Metzler, V.; Zhang, J. A Review of Lithium Deposition in Lithium-Ion and Lithium Metal Secondary Batteries. J. Power Sources 2014, 254, 168-182.

(40) Jäckle, M.; Groß, A. Microscopic Properties of Lithium, Sodium, and Magnesium Battery Anode Materials Related to Possible Dendrite Growth. J. Chem. Phys. 2014, 141, 174710.

(41) Wood, K. N.; Noked, M.; Dasgupta, N. P. Lithium Metal Anodes: Toward an Improved Understanding of Coupled Morphological, Electrochemical, and Mechanical Behavior. ACS Energy Lett. 2017, 2, 664-672.

(42) Yoo, H. D.; Shterenberg, I.; Gofer, Y.; Gershinsky, G.; Pour, N.; Aurbach, D. Mg Rechargeable Batteries: An On-Going Challenge. Energy Environ. Sci. 2013, 6, 2265-2279.

(43) Muldoon, J.; Bucur, C. B.; Gregory, T. Quest for Nonaqueous Multivalent Secondary Batteries: Magnesium and Beyond. Chem. Rev. 2014, 114, 11683-11720.

(44) Park, M.-S.; Kim, J.-G.; Kim, Y.-J.; Choi, N.-S.; Kim, J.-S. Recent Advances in Rechargeable Magnesium Battery Technology: A Review of the Field's Current Status and Prospects. Isr. J. Chem. 2015, 55, 570-585.

(45) Aurbach, D.; Lu, Z.; Schechter, A.; Gofer, Y.; Gizbar, H.; Turgeman, R.; Cohen, Y.; Moshkovich, M.; Levi, E. Prototype Systems for Rechargeable Magnesium Batteries. Nature 2000, 407, $724-727$.

(46) Shterenberg, I.; Salama, M.; Gofer, Y.; Levi, E.; Aurbach, D. The Challenge of Developing Rechargeable Magnesium Batteries. MRS Bull. 2014, 39, 453-460.

(47) Canepa, P.; Sai Gautam, G.; Hannah, D. C.; Malik, R.; Liu, M.; Gallagher, K. G.; Persson, K. A.; Ceder, G. Odyssey of Multivalent Cathode Materials: Open Questions and Future Challenges. Chem. Rev. 2017, 117, 4287-4341.

(48) Pan, H.; Hu, Y.-S.; Chen, L. Room-Temperature Stationary Sodium-Ion Batteries for Large-Scale Electric Energy Storage. Energy Environ. Sci. 2013, 6, 2338-2360.

(49) Emsley, J. Nature's Building Blocks: An A-Z Guide to the Elements; OUP Oxford: Oxford, England, 2011; p 699-699.

(50) Mohtadi, R.; Mizuno, F. Magnesium Batteries: Current State of the Art, Issues and Future Perspectives. Beilstein J. Nanotechnol. 2014, 5, 1291-1311.

(51) Yagi, S.; Ichitsubo, T.; Shirai, Y.; Yanai, S.; Doi, T.; Murase, K.; Matsubara, E. A Concept of Dual-Salt Polyvalent-Metal Storage Battery. J. Mater. Chem. A 2014, 2, 1144-1149.

(52) Tutusaus, O.; Mohtadi, R. Paving the Way towards Highly Stable and Practical Electrolytes for Rechargeable Magnesium Batteries. ChemElectroChem 2015, 2, 51-57.

(53) Shao, Y.; Liu, T.; Li, G.; Gu, M.; Nie, Z.; Engelhard, M.; Xiao, J.; Lv, D.; Wang, C.; Zhang, J.-G.; Liu, J. Coordination Chemistry in Magnesium Battery Electrolytes: How Ligands Affect Their Performance. Sci. Rep. 2013, 3, 3130.

(54) Vardar, G.; Sleightholme, A. E. S.; Naruse, J.; Hiramatsu, H.; Siegel, D. J.; Monroe, C. W. Electrochemistry of Magnesium Electrolytes in Ionic Liquids for Secondary Batteries. ACS Appl. Mater. Interfaces 2014, 6, 18033-18039.

(55) Canepa, P.; Gautam, G. S.; Malik, R.; Jayaraman, S.; Rong, Z.; Zavadil, K. R.; Persson, K.; Ceder, G. Understanding the Initial Stages of Reversible $\mathrm{Mg}$ Deposition and Stripping in Inorganic Nonaqueous Electrolytes. Chem. Mater. 2015, 27, 3317-3325.

(56) Rajput, N. N.; Qu, X.; Sa, N.; Burrell, A. K.; Persson, K. A. The Coupling between Stability and Ion Pair Formation in Magnesium Electrolytes from First-Principles Quantum Mechanics and Classical Molecular Dynamics. J. Am. Chem. Soc. 2015, 137, 3411-3420. 
(57) Yoo, H. D.; Liang, Y.; Dong, H.; Lin, J.; Wang, H.; Liu, Y.; Ma, L.; Wu, T.; Li, Y.; Ru, Q.; Jing, Y.; An, Q.; Zhou, W.; Guo, J.; Lu, J.; Pantelides, S. T.; Qian, X.; Yao, Y. Fast Kinetics of Magnesium Monochloride Cations in Interlayer-expanded Titanium Disulfide for Magnesium Rechargeable Batteries. Nat. Commun. 2017, 8, 339.

(58) Doe, R. E.; Han, R.; Hwang, J.; Gmitter, A. J.; Shterenberg, I.; Yoo, H. D.; Pour, N.; Aurbach, D. Novel, Electrolyte Solutions Comprising Fully Inorganic Salts with High Anodic Stability for Rechargeable Magnesium Batteries. Chem. Commun. 2014, 50, 243245.

(59) Zhang, Z.; Cui, Z.; Qiao, L.; Guan, J.; Xu, H.; Wang, X.; Hu, P.; Du, H.; Li, S.; Zhou, X.; Dong, S.; Liu, Z.; Cui, G.; Chen, L. Novel Design Concepts of Efficient $\mathrm{Mg}$-Ion Electrolytes toward HighPerformance Magnesium-Selenium and Magnesium-Sulfur Batteries. Adv. Energy Mater. 2017, 7, 1602055.

(60) Tutusaus, O.; Mohtadi, R.; Arthur, T. S.; Mizuno, F.; Nelson, E. G.; Sevryugina, Y. V. An Efficient Halogen-Free Electrolyte for Use in Rechargeable Magnesium Batteries. Angew. Chem., Int. Ed. 2015, 54, 7900-7904.

(61) Zhao-Karger, Z.; Zhao, X.; Wang, D.; Diemant, T.; Behm, R. J.; Fichtner, M. Performance Improvement of Magnesium Sulfur Batteries with Modified Non-Nucleophilic Electrolytes. Adv. Energy Mater. 2015, 5, 1401155.

(62) Muldoon, J.; Bucur, C. B.; Gregory, T. Fervent Hype behind Magnesium Batteries: An Open Call to Synthetic ChemistsElectrolytes and Cathodes Needed. Angew. Chem., Int. Ed. 2017, 56, 12064-12084.

(63) Huie, M. M.; Bock, D. C.; Takeuchi, E. S.; Marschilok, A. C.; Takeuchi, K. J. Cathode Materials for Magnesium and MagnesiumIon Based Batteries. Coord. Chem. Rev. 2015, 287, 15-27.

(64) Saha, P.; Datta, M. K.; Velikokhatnyi, O. I.; Manivannan, A.; Alman, D.; Kumta, P. N. Rechargeable Magnesium Battery: Current Status and Key Challenges for the Future. Prog. Mater. Sci. 2014, 66, $1-86$.

(65) Zhou, B.; Shi, H.; Cao, R.; Zhang, X.; Jiang, Z. Theoretical Study on the Initial Stage of a Magnesium Battery Based on a $\mathrm{V}_{2} \mathrm{O}_{5}$ Cathode. Phys. Chem. Chem. Phys. 2014, 16, 18578-18585.

(66) Jiao, L.; Yuan, H.; Wang, Y.; Cao, J.; Wang, Y. Mg Intercalation Properties Into Open-Ended Vanadium Oxide Nanotubes. Electrochem. Commun. 2005, 7, 431-436.

(67) Nam, K. W.; Kim, S.; Lee, S.; Salama, M.; Shterenberg, I.; Gofer, Y.; Kim, J.-S.; Yang, E.; Park, C. S.; Kim, J.-S.; Lee, S.-S.; Chang, W.-S.; Doo, S.-G.; Jo, Y. N.; Jung, Y.; Aurbach, D.; Choi, J. W. The High Performance of Crystal Water Containing Manganese Birnessite Cathodes for Magnesium Batteries. Nano Lett. 2015, 15, 4071-4079.

(68) Kim, C.; Phillips, P. J.; Key, B.; Yi, T.; Nordlund, D.; Yu, Y.-S.; Bayliss, R. D.; Han, S.-D.; He, M.; Zhang, Z.; Burrell, A. K.; Klie, R. F.; Cabana, J. Direct Observation of Reversible Magnesium Ion Intercalation into a Spinel Oxide Host. Adv. Mater. 2015, 27, 33773384

(69) Wang, R. Y.; Wessells, C. D.; Huggins, R. A.; Cui, Y. Highly Reversible Open Framework Nanoscale Electrodes for Divalent Ion Batteries. Nano Lett. 2013, 13, 5748-5752.

(70) Gershinsky, G.; Yoo, H. D.; Gofer, Y.; Aurbach, D. Electrochemical and Spectroscopic Analysis of $\mathrm{Mg}^{2+}$ Intercalation into Thin Film Electrodes of Layered Oxides: $\mathrm{V}_{2} \mathrm{O}_{5}$ and $\mathrm{MoO}_{3}$. Langmuir 2013, 29, 10964-10972.

(71) Liu, B.; Luo, T.; Mu, G.; Wang, X.; Chen, D.; Shen, G. Rechargeable Mg-Ion Batteries Based on $\mathrm{WSe}_{2}$ Nanowire Cathodes. ACS Nano 2013, 7, 8051-8058.

(72) NuLi, Y.; Zheng, Y.; Wang, F.; Yang, J.; Minett, A. I.; Wang, J.; Chen, J. MWNT/C/ $/ \mathrm{Mg}_{1.03} \mathrm{Mn}_{0.97} \mathrm{SiO}_{4}$ Hierarchical Nanostructure for Superior Reversible Magnesium Ion Storage. Electrochem. Commun. 2011, 13, 1143-1146.

(73) Rasul, S.; Suzuki, S.; Yamaguchi, S.; Miyayama, M. Synthesis and Electrochemical Behavior of Hollandite $\mathrm{MnO}_{2} /$ Acetylene Black Composite Cathode for Secondary Mg-Ion Batteries. Solid State Ionics 2012, 225, 542-546.
(74) Lee, S. H.; DiLeo, R. A.; Marschilok, A. C.; Takeuchi, K. J.; Takeuchi, E. S. Sol Gel Based Synthesis and Electrochemistry of Magnesium Vanadium Oxide: A Promising Cathode Material for Secondary Magnesium Ion Batteries. ECS Electrochem. Lett. 2014, 3, A $87-$ A90.

(75) Tutusaus, O.; Mohtadi, R. Paving the Way towards Highly Stable and Practical Electrolytes for Rechargeable Magnesium Batteries. ChemElectroChem 2015, 2, 51-57.

(76) Sun, X.; Bonnick, P.; Nazar, L. F. Layered TiS 2 Positive Electrode for Mg Batteries. ACS Energy Lett. 2016, 1, 297-301.

(77) Tashiro, Y.; Taniguchi, K.; Miyasaka, H. The Effect of Anionsublattice Structure on the Displacement Reaction in Copper Sulfide Cathodes of Rechargeable Magnesium Batteries. Chem. Lett. 2017, 46, $1240-1242$

(78) Huie, M. M.; Bock, D. C.; Takeuchi, E. S.; Marschilok, A. C.; Takeuchi, K. J. Cathode Materials for Magnesium and MagnesiumIon Based Batteries. Coord. Chem. Rev. 2015, 287, 15-27.

(79) Sun, X.; Bonnick, P.; Duffort, V.; Liu, M.; Rong, Z.; Persson, K. A.; Ceder, G.; Nazar, L. F. A High Capacity Thiospinel Cathode for Mg Batteries. Energy Environ. Sci. 2016, 9, 2273-2277.

(80) Arsentev, M.; Missyul, A.; Petrov, A. V.; Hammouri, M. TiS 3 Magnesium Battery Material: Atomic-Scale Study of Maximum Capacity and Structural Behavior. J. Phys. Chem. C 2017, 121, $15509-15515$.

(81) Xiong, F.; Fan, Y.; Tan, S.; Zhou, L.; Xu, Y.; Pei, C.; An, Q.; Mai, L. Magnesium Storage Performance and Mechanism of CuS Cathode. Nano Energy 2018, 47, 210-216.

(82) Vinayan, B. P.; Zhao-Karger, Z.; Diemant, T.; Chakravadhanula, V. S. K.; Schwarzburger, N. I.; Cambaz, M. A.; Behm, R. J.; Kubel, C.; Fichtner, M. Performance Study of Magnesium-Sulfur Battery Using a Graphene Based Sulfur Composite Cathode Electrode and a Non-nucleophilic Mg Electrolyte. Nanoscale 2016, 8, 3296-3306.

(83) Lossius, L. P.; Emmenegger, F. Plating of Magnesium From Organic Solvents. Electrochim. Acta 1996, 41, 445-447.

(84) Shao, Y.; Gu, M.; Li, X.; Nie, Z.; Zuo, P.; Li, G.; Liu, T.; Xiao, J.; Cheng, Y.; Wang, C.; Zhang, J.-G.; Liu, J. Highly Reversible Mg Insertion in Nanostructured Bi for Mg Ion Batteries. Nano Lett. 2014, $14,255-260$.

(85) Murgia, F.; Stievano, L.; Monconduit, L.; Berthelot, R. Insight Into the Electrochemical Behavior of Micrometric $\mathrm{Bi}$ and $\mathrm{Mg}_{3} \mathrm{Bi}_{2}$ as High Performance Negative Electrodes for Mg Batteries. J. Mater. Chem. A 2015, 3, 16478-16485.

(86) Arthur, T. S.; Singh, N.; Matsui, M. Electrodeposited Bi, Sb and $\mathrm{Bi}_{1-\mathrm{x}} \mathrm{Sb}_{\mathrm{x}}$ Alloys as Anodes for Mg-Ion Batteries. Electrochem. Commun. 2012, 16, 103-106.

(87) Liu, Z.; Lee, J.; Xiang, G.; Glass, H. F. J.; Keyzer, E. N.; Dutton, S. E.; Grey, C. P. Insights Into the Electrochemical Performances of Bi Anodes for $\mathrm{Mg}$ Ion Batteries Using ${ }^{25} \mathrm{Mg}$ Solid State NMR Spectroscopy. Chem. Commun. 2017, 53, 743-746.

(88) Sedighi, M.; Arghavani Nia, B.; Zarringhalam, H.; Moradian, R. Density Functional Theory Study of the Structural and Electronic Properties of $\mathrm{Mg}_{3} \mathrm{Bi}_{2}$ in Hexagonal and Cubic Phases. Eur. Phys. J.: Appl. Phys. 2013, 61, 10103.

(89) Jin, W.; Li, Z.; Wang, Z.; Fu, Y. Q. Mg Ion Dynamics in Anode Materials of $\mathrm{Sn}$ and Bi for Mg-Ion Batteries. Mater. Chem. Phys. 2016, $182,167-172$.

(90) Benmayza, A.; Ramanathan, M.; Singh, N.; Mizuno, F.; Prakash, J. Electrochemical and Thermal Studies of Bismuth Electrodes for Magnesium-Ion Cells. J. Electrochem. Soc. 2015, 162, A1630-A1635.

(91) Ramanathan, M.; Benmayza, A.; Prakash, J.; Singh, N.; Mizuno, F. A Porous Electrode Model for the Magnesiation and Demagnesiation of a Bismuth Electrode in Rechargeable Magnesium-Ion Cells. J. Electrochem. Soc. 2016, 163, A477-A487.

(92) DiLeo, R. A.; Zhang, Q.; Marschilok, A. C.; Takeuchi, K. J.; Takeuchi, E. S. Composite Anodes for Secondary Magnesium Ion Batteries Prepared via Electrodeposition of Nanostructured Bismuth 
on Carbon Nanotube Substrates. ECS Electrochem. Lett. 2015, 4, A10-A14.

(93) Wang, W.; Liu, L.; Wang, P.-F.; Zuo, T.-T.; Yin, Y.-X.; Wu, N.; Zhou, J.-M.; Wei, Y.; Guo, Y.-G. A Novel Bismuth-Based Anode Material with a Stable Alloying Process by the Space Confinement of an In Situ Conversion Reaction for a Rechargeable Magnesium Ion Battery. Chem. Commun. 2018, 54, 1714-1717.

(94) Penki, T. R.; Valurouthu, G.; Shivakumara, S.; Sethuraman, V. A.; Munichandraiah, N. In Situ Synthesis of Bismuth (Bi)/Reduced Graphene Oxide (RGO) Nanocomposites as High-Capacity Anode Materials for a Mg-Ion Battery. New J. Chem. 2018, 42, 5996-6004.

(95) Singh, N.; Arthur, T. S.; Ling, C.; Matsui, M.; Mizuno, F. A high Energy-Density Tin Anode for Rechargeable Magnesium-Ion Batteries. Chem. Commun. 2013, 49, 149-151.

(96) Nguyen, D. T.; Tran, X. M.; Kang, J.; Song, S. W. Magnesium Storage Performance and Surface Film Formation Behavior of Tin Anode Material. ChemElectroChem 2016, 3, 1813-1819.

(97) Periyapperuma, K.; Tran, T. T.; Purcell, M. I.; Obrovac, M. N. The Reversible Magnesiation of $\mathrm{Pb}$. Electrochim. Acta 2015, 165, $162-165$.

(98) Murgia, F.; Weldekidan, E. T.; Stievano, L.; Monconduit, L.; Berthelot, R. First Investigation of Indium-Based Electrode in $\mathrm{Mg}$ Battery. Electrochem. Commun. 2015, 60, 56-59.

(99) Murgia, F.; Laurencin, D.; Weldekidan, E. T.; Stievano, L.; Monconduit, L.; Doublet, M.-L.; Berthelot, R. Electrochemical Mg Alloying Properties Along the $\mathrm{Sb}_{1-\mathrm{x}} \mathrm{Bi}_{\mathrm{x}}$ Solid Solution. Electrochim. Acta 2018, 259, 276-283.

(100) Murgia, F.; Monconduit, L.; Stievano, L.; Berthelot, R. Electrochemical Magnesiation of the Intermetallic InBi Through Conversion-Alloying Mechanism. Electrochim. Acta 2016, 209, 730736.

(101) Parent, L. R.; Cheng, Y.; Sushko, P. V.; Shao, Y.; Liu, J.; Wang, C.-M.; Browning, N. D. Realizing the Full Potential of Insertion Anodes for $\mathrm{Mg}$-Ion Batteries Through the Nanostructuring of Sn. Nano Lett. 2015, 15, 1177-1182.

(102) Cheng, Y.; Shao, Y.; Parent, L. R.; Sushko, M. L.; Li, G.; Sushko, P. V.; Browning, N. D.; Wang, C.; Liu, J. Interface Promoted Reversible $\mathrm{Mg}$ Insertion in Nanostructured Tin-Antimony Alloys. Adv. Mater. 2015, 27, 6598-6605.

(103) Nayeb-Hashemi, A. A.; Clark, J. B. The Bi-Mg (BismuthMagnesium) System. Bull. Alloy Phase Diagrams 1985, 6, 528-533.

(104) Barnes, A. C.; Guo, C.; Howells, W. S. Fast-Ion Conduction and the Structure of $\beta-\mathrm{Mg}_{3} \mathrm{Bi}_{2}$. J. Phys.: Condens. Matter 1994, 6, L467-L471.

(105) He, M.; Protesescu, L.; Caputo, R.; Krumeich, F.; Kovalenko, M. V. A General Synthesis Strategy for Monodisperse Metallic and Metalloid Nanoparticles (In, Ga, Bi, Sb, Zn, Cu, Sn, and Their Alloys) via In Situ Formed Metal Long-Chain Amides. Chem. Mater. 2015, 27, 635-647.

(106) Law, M.; Luther, J. M.; Song, Q.; Hughes, B. K.; Perkins, C. L.; Nozik, A. J. Structural, Optical, and Electrical Properties of PbSe Nanocrystal Solids Treated Thermally or with Simple Amines. J. Am. Chem. Soc. 2008, 130, 5974-5985.

(107) Talapin, D. V.; Murray, C. B. PbSe Nanocrystal Solids for nand p-Channel Thin Film Field-Effect Transistors. Science 2005, 310, 86-89.

(108) Zhang, H.; Hu, B.; Sun, L.; Hovden, R.; Wise, F. W.; Muller, D. A.; Robinson, R. D. Surfactant Ligand Removal and Rational Fabrication of Inorganically Connected Quantum Dots. Nano Lett. 2011, 11, 5356-5361.

(109) Prehal, C.; Weingarth, D.; Perre, E.; Lechner, R. T.; Amenitsch, H.; Paris, O.; Presser, V. Tracking the Structural Arrangement of Ions in Carbon Supercapacitor Nanopores using In Situ Small-Angle X-ray Scattering. Energy Environ. Sci. 2015, 8, 17251735.

(110) Rieker, T. P.; Hindermann-Bischoff, M.; Ehrburger-Dolle, F. Small-Angle X-ray Scattering Study of the Morphology of Carbon Black Mass Fractal Aggregates in Polymeric Composites. Langmuir 2000, 16, 5588-5592.
(111) Glatter, O.; Kratky, O. Small-Angle X-ray Scattering; Academic Press: New York, 1982.

(112) Lancry, E.; Levi, E.; Mitelman, A.; Malovany, S.; Aurbach, D. Molten Salt Synthesis (MSS) of $\mathrm{Cu}_{2} \mathrm{Mo}_{6} \mathrm{~S}_{8}-\mathrm{New}$ Way for Largescale Production of Chevrel Phases. J. Solid State Chem. 2006, 179, 1879-1882.

(113) Perdew, J. P.; Burke, K.; Ernzerhof, M. Generalized Gradient Approximation Made Simple. Phys. Rev. Lett. 1996, 77, 3865-3868.

(114) Ceperley, D.; Alder, B. J. Ground State of the Electron Gas by a Stochastic Method. Phys. Rev. Lett. 1980, 45, 566-569.

(115) Perdew, J. P.; Zunger, A. Self-Interaction Correction to Density-Functional Approximations for Many-Electron Systems. Phys. Rev. B: Condens. Matter Mater. Phys. 1981, 23, 5048-5079. 